\title{
Influence of ceramic material, thickness of restoration and cement layer on stress distribution of occlusal veneers
}

\begin{abstract}
João Paulo Mendes TRIBST(a) Amanda Maria de Oliveira DAL PIVA(a) Marcela Moreira PENTEADO(a) Alexandre Luiz Souto BORGES(a) Marco Antonio BOTTINO(a)
\end{abstract}

(a) Universidade Estadual Paulista - Unesp, Instituto de Ciência e Tecnologia, Department of Dental Materials and Prosthodontics, Post-Graduate Program in Restorative Dentistry (Prosthodontic), São José dos Campos, SP, Brazil.

Declaration of Interest: The authors certify that they have no commercial or associative interest that represents a conflict of interest in connection with the manuscript.

\section{Corresponding Author:}

Amanda Maria de Oliveira Dal Piva

E-mail: amodalpiva@gmail.com

htps://doi.org/10.1590/1807-3107bor-2018.vol32.0118

Submitted: May 15, 20

Accepted for publication: September 29, 2018

Last revision: October 17, 2018
Abstract: The aim of this study was to evaluate stress distribution in an occlusal veneer according to the restorative material, restoration thickness, and cement layer thickness. A tridimensional model of a human maxillary first molar with an occlusal veneer preparation was constructed using a modeling software of finite element analysis. The model was replicated 9 times to evaluate the factors: restoration thickness $(0.6,1.2$, and $1.8 \mathrm{~mm})$ and cement layer thickness $(100,200$, and $300 \mu \mathrm{m})$. Then, each model received different restorative materials (High Translucency Zirconia - [YZHT], Lithium Disilicate - [LD], Zirconia Reinforced Lithium Silicate - [ZLS], Feldspathic - [F], and Hybrid Ceramic - $[\mathrm{HC}]$ ), totaling forty-five groups. An axial load (600 $\mathrm{N})$ was applied on the occlusal face for static structural analysis. Solids were considered isotropic, homogeneous, and linearly elastic. Contacts were considered perfectly bonded. Fixation occurred in the dental root and a mechanical static structural analysis was performed. Descriptive statistical analysis and one-way ANOVA $(\alpha=10 \%)$ were performed for tensile stress peak values in the restoration and cement layer. The difference between groups was compared using the Tukey's test with $10 \%$ significance to match the percentage of the mesh convergence test. According to the results, the cement layer thickness did not influence stress distribution in the restoration $(p \geq 0.10)$. The thicker the restoration, the higher the tensile stress concentration in the restoration. The graphs showed higher stress concentration in the YZHT, followed by LD, F, ZLS, and HC. Also, the restorative material influenced stress concentration on the cement layer, which decreased according to the sequence $\mathrm{HC}>\mathrm{YZHT}>\mathrm{ZLS}>\mathrm{LD}>\mathrm{F}$. HC stood out for causing the least stress concentration in the restoration. Cement layer thickness did not interfere in the mechanical performance of the restorations.

Keywords: Finite Element Analysis; Ceramics; Dental Veneer; Tooth Wear.

\section{Introduction}

Tabletop or ultrathin occlusal veneers are a contemporary restorative approach indicated for teeth with occlusal wear. They consist of an important therapeutic modality to recover the occlusal vertical dimension of patients with great occlusal wear related to a parafunctional habit ${ }^{1}$ or physiological processes such as erosions ${ }^{2}$. The main advantage of occlusal 
veneers is the recovery of the masticatory function with maximum preservation of dental structure ${ }^{2,3}$ being a conservative option to traditional onlays ${ }^{4}$ and complete coverage crowns. ${ }^{2,5}$ Other advantages are the possibility to predict the final result with temporary restorations ${ }^{6}$ and the easiness of cementation. ${ }^{7}$

Although direct composite resins restorations are commonly made, ${ }^{5,6}$ the use of indirect ceramic materials may provide greater predictability to the treatment in recovering the occlusal vertical dimension during a prolonged time. ${ }^{4,5}$ However, multiple factors interfere in restoration dynamics such as the final appearance of the dental preparation, restoration geometry and thickness, as well as the mechanical performance of the ceramic material associated with the adhesive technique. ${ }^{8}$

With the advances in CAD/CAM (computer aided design/Computer aided manufacturing) materials and resin cements, ${ }^{9}$ the loss of dental structure can be minimized using conservative preparations for occlusal veneers. ${ }^{2,6}$ Several studies have evaluated fracture ${ }^{3,5,6}$ and fatigue resistance ${ }^{5}$ of restorations made in ceramics or composite resin ${ }^{4,5}$ of different thicknesses. ${ }^{6}$ The authors observed that thickness is not as influential as the material under a compressive load, thus allowing tabletop veneers to resist loads higher than masticatory ones. ${ }^{6}$ Until now, no clinical trial or case report has evaluated the most common type of failure of occlusal veneers. However, according to laboratorial fatigue tests, cracks in the restoration and debonding are the most common failure types. ${ }^{5,10}$ Therefore, it is important to understand how stress from masticatory forces is distributed ${ }^{4,11}$ in occlusal veneers. Computational simulations from modeling the structures to be evaluated $^{4,11,12,13}$ allows the visualization of stress concentration regions. As assessed in in vitro studies, defects in stress regions are the origin of fractures.

This study aimed to evaluate the stress distribution in an occlusal veneer restoration according to the restorative material, restoration thickness, and cement thickness. The hypotheses were: a) there would be differences in stress distribution in the restoration and cement layer according to the occlusal veneer thickness; b) a thicker cement layer could negatively influence the mechanical response of the occlusal veneer and resin cement; and c) different ceramic materials would exhibit different mechanical behaviors under the same conditions.

\section{Methodology}

\section{Finite element analysis pre-processing}

For finite element (FE) analysis (FEA), a tridimensional (3D) model of a human maxillary first molar was generated according to anatomical references containing enamel, dentin and periodontal ligament. The pulp chamber and root canals were generated as an empty space in the dentin ${ }^{4,11}$ without elastic modulus. This 3D-FE model was inserted in a fixation cylinder that simulated bone tissue. ${ }^{11,12} \mathrm{Next}$, the tooth was replicated in 9 identical models with occlusal wear characteristic of patients with severe dental erosion. Three levels of wear were simulated: ${ }^{4} 0.6,1.2$, and $1.8 \mathrm{~mm}$. For that, the occlusal preparation followed the cusps convergence according to Magne et al., ${ }^{5}$ simulating the rehabilitation with veneers of respective thicknesses for each model. The geometry of the occlusal preparation was based on a previous study whose minimum restoration thickness was $0.6 \mathrm{~mm}$ at the center and $1.2 \mathrm{~mm}$ at the cusps $^{5}$ (Figure 1). From this definition, the restoration thickness was increased 2- and 3-fold, resulting in 1.2 $\mathrm{mm}$ and $1.8 \mathrm{~mm}$ of minimum occlusal thickness. Three cement layer thicknesses were also evaluated: 100, 200, and $300 \mu \mathrm{m} \cdot{ }^{14}$ Table 1 summarizes the group distribution according to 9 models considering the restoration and cement layer thicknesses. For the complete analysis, each model's crown received 5 different materials, totaling 45 groups.

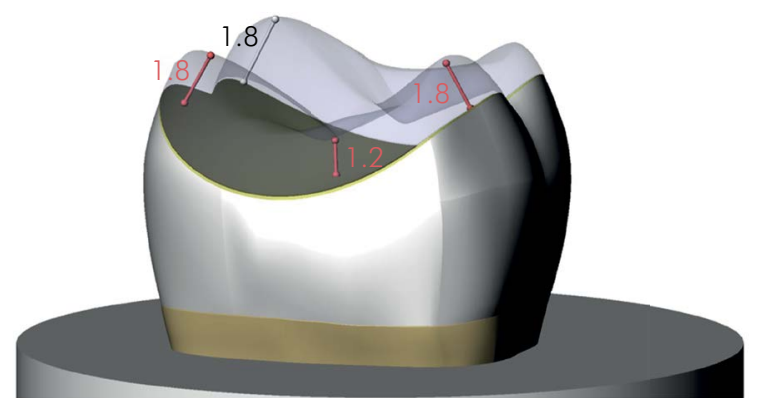

Figure 1. Three-dimensional model of a restored molar with occlusal veneer of 1.2-mm minimum thickness. 
Table 1. Group distribution according to restoration thickness, cement layer thickness, and restorative material. Number of elements and nodes are shown for each 3D-FEA model.

\begin{tabular}{|c|c|c|c|c|}
\hline $\begin{array}{l}\text { Restoration } \\
\text { thickness (mm) }\end{array}$ & $\begin{array}{l}\text { Cementing layer } \\
\text { thickness }(\mu \mathrm{m})\end{array}$ & Restorative material & Number of elements & Number of nodes \\
\hline \multirow{3}{*}{0.6} & 100 & \multirow{7}{*}{$\begin{array}{c}\text { High translucency zirconia } \\
\text { Lithium disilicate } \\
\text { Zirconia reinforced lithium silicate } \\
\text { Feldspathic } \\
\text { Hybrid ceramic }\end{array}$} & 38,456 & 130,36 \\
\hline & 200 & & 39,874 & 131,798 \\
\hline & 300 & & 39,908 & 132,842 \\
\hline \multirow{3}{*}{1.2} & 100 & & 41,34 & 132,912 \\
\hline & 200 & & 41,65 & 133,174 \\
\hline & 300 & & 41,848 & 133,804 \\
\hline \multirow{3}{*}{1.8} & 100 & & 43,568 & 136,166 \\
\hline & 200 & & 43,13 & 136,48 \\
\hline & 300 & & 43,962 & 136,588 \\
\hline
\end{tabular}

\section{Boundary condition and mesh generation}

The geometries were imported to CAE ANSYS software (ANSYS 17.2, ANSYS Inc., Houston, USA) in STEP format and tetrahedral elements formed the mesh. A convergence test of $10 \%$ mesh contro ${ }^{12}$ determined the number of elements and nodes; thus, the subdivision of the complex geometry into a finite number of elements did not interfere in the results. The properties of the materials and structures were attributed to each solid component with isotropic, homogeneous, and linearly elastic behavior. Young's modulus and Poisson's ratio were reported based on the literature (Table 2), 15,16,17,18,19,20,21,22 and all contacts were ideally bonded. Five restorative materials for the 9 models (according to restoration and cement thicknesses) were simulated: high translucency zirconia (YZHT), lithium disilicate (LD), zirconia reinforced lithium silicate (ZLS), feldspathic (F), and hybrid ceramic (HC), totaling 45 groups. The group distributions as well as the mesh and node numbers are summarized in Table 1.

\section{FEA processing}

Load application $(600 \mathrm{~N})$ occurred similar to the study by Ausiello et al., ${ }^{13}$ a methodology that considers the contact between a food bolus and the tooth surface during the closing phase of the chewing cycle. A cylinder base was selected for the system fixation, ensuring only the movement constraint on the $\mathrm{Z}$ axis so that the strain generated in all directions was computed. Results in the restoration and cement layer were obtained using maximum principal stress for quantitative analysis and minimum principal stress for a qualitative approach.

\section{Statistical analysis}

After the mechanical static structural analysis, the tensile stress peaks on the internal surfaces of the restoration and cement layer were exported in spreadsheets, according to the element number corresponding to the numerical calculation. The 100 highest values were selected for each structure (restoration and cement) of all 45 groups, totaling 9,000 values for tensile stress in $\mathrm{MPa}$. The data were analyzed by descriptive statistics (mean and standard deviation), one-way ANOVA for each studied factor, followed by Tukey's test for differences between groups. All tests were considered significant at $10 \%$ due to the correspondence of the mesh convergence test.

\section{Results}

In the compressive load situation, the maximum principal stress (Figure 2) was concentrated at the center of the occlusal veneer, and tensile stress (Figure 3) in the intaglio surface. Figure 2 shows that the higher the restorative material elastic modulus, the higher is the compressive stress concentration in the occlusal veneer external surface. The same behavior is observed for the tensile stress concentration in the intaglio surface: the higher the material elastic modulus, the higher the tensile stress concentration (Figure 3). The influence of each factor on the concentration of tensile stresses on the restoration and cement layer was evaluated with the statistical analysis. Figure 4 shows histograms ${ }^{23}$ of stress data that were plotted for each individual 
Hybrid Ceramic / ZLS / Feldspathic / Lithium Disilicate / Zirconia
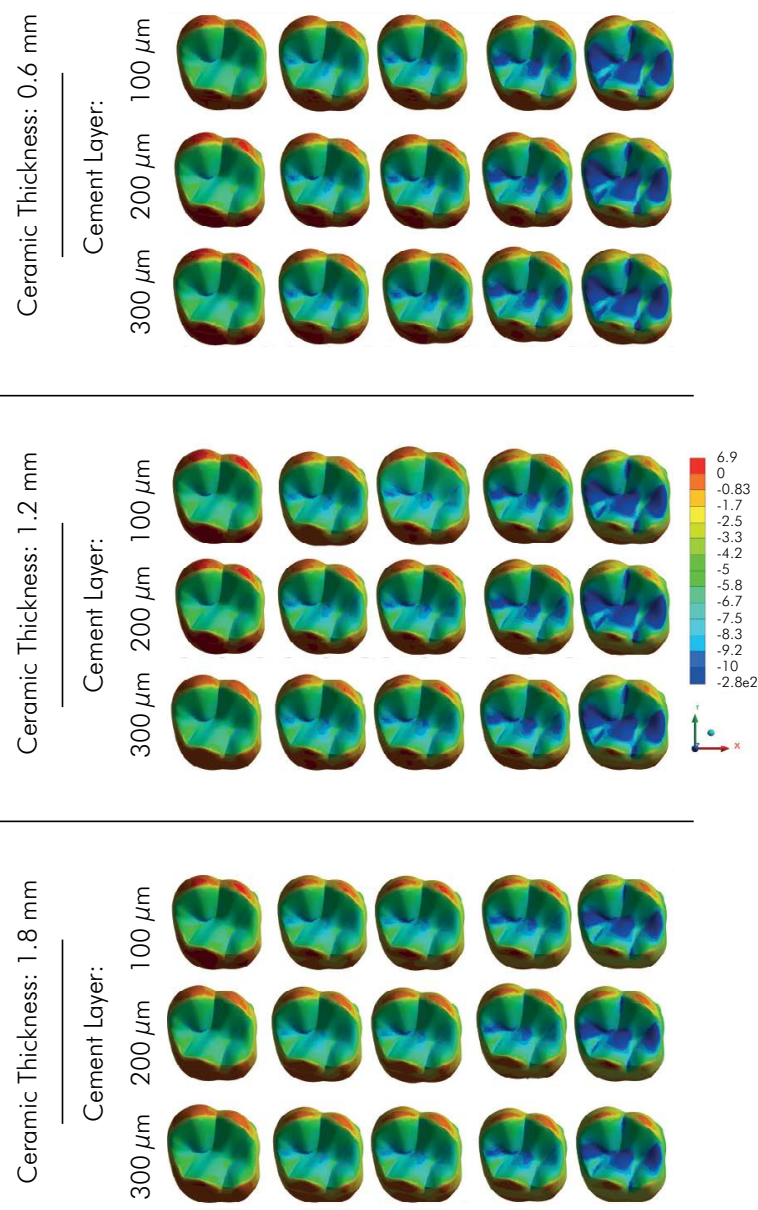

Figure 2. Compressive stress in teeth restored with occlusal veneers in an occlusal view.

Table 2. Mechanical properties of materials and structures used in the study.

\begin{tabular}{lcc}
\hline Material or structure & $\begin{array}{c}\text { Elastic } \\
\text { modulus }\end{array}$ & $\begin{array}{c}\text { Poisson } \\
\text { ratio }\end{array}$ \\
\hline Enamel $^{15}$ & 84.1 & 0.33 \\
Dentin $^{15}$ & 18.6 & 0.32 \\
Periodontal ligament $^{16}$ & 0.069 & 0.45 \\
Fixture cylinder $^{17}$ & 3.6 & 0.3 \\
High translucency zirconia $^{18}$ & 210 & 0.33 \\
Lithium disilicate $^{19}$ & 95 & 0.25 \\
Zirconia reinforced lithium silicate $^{20}$ & 70 & 0.23 \\
Feldspathic $^{21}$ & 48.7 & 0.23 \\
Hybrid ceramic $^{22}$ & 30 & 0.28 \\
Resin cement $^{22}$ & 7.5 & 0.25 \\
\hline
\end{tabular}

factor to facilitate visualization of significant results, considering the same confidence interval as the computational results of mesh convergence. For each histogram, the $\mathrm{X}$ axis shows the calculated stress peaks in $\mathrm{MPa}$, and the $\mathrm{Y}$ axis shows the data density according to the variability on the evaluated elements; thus, higher curves indicate lower variability and data farther to the right indicate higher stress peaks. Descriptive statistics, $p$ value, and homogeneous groups are described in Figure 4. For the restoration, the cement layer thickness was not significant $(p=0.167)$, different from restorative material $(p=0.000)$ and restoration thickness $(p=$ $0.009)$. However, the ceramic material $(p=0.001)$, thickness of restoration $(p=0.001)$, and cement layer $(p=0.012)$ were significant for the tensile stress generation on the cement layer. The bar graphs show individual stress peaks (Figure 5). YZHT showed the highest stress peaks for the restoration while HC showed the highest peaks for the cement layer, corroborating with the stress maps.

\section{Discussion}

This study evaluated five ceramic materials for occlusal veneer made in three thicknesses and cemented with different thicknesses of cement. The first hypothesis was accepted, because the restorative material thickness influenced the restoration and the resin cement biomechanics. The second hypothesis was rejected because the cement thickness was only significant for the stress generated in the cement itself. The third hypothesis was also accepted since each simulated material (different elastic modulus) had a significant influence on the occlusal veneer and resin cement mechanical response.

The results demonstrate that the restorative material can directly influence the prognosis in the long term. Each material has a specific hardness, which is reflected in various elastic modulus (in the present study, from 30 to $220 \mathrm{GPa}$ ) allowing different concentrations of tensile stresses on the crown intaglio surface. .,12,24,25 $^{2}$ In this case, the most affected site was the internal surface of the restoration, which is suggested to be the initiation region for slow crack propagation. ${ }^{26}$ Defects on the surface may be the failure origin when 

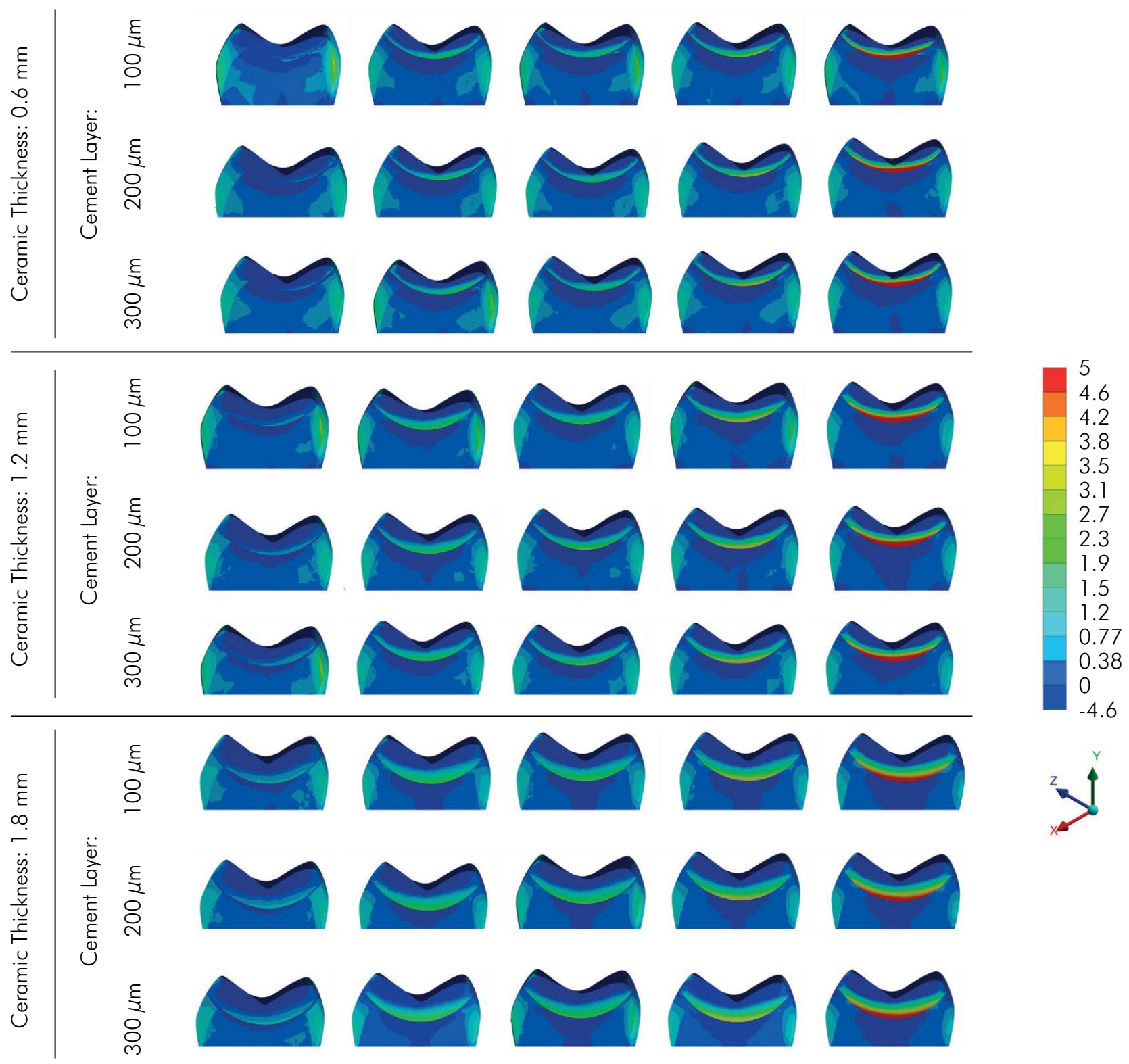

Figure 3. Tensile stress in teeth restored with occlusal veneers in sagittal section.

a high tensile stress occurs near them. Zirconia has the highest elastic modulus and consequently it showed higher tensile stress concentrated in its intaglio surface (Figure 3). However, due to its hardness property, ${ }^{27}$ it is difficult to affirm that this material could fail earlier than the simulated vitreous ceramics. The flexural strength of YZHT is twice as high as that of LD. ${ }^{19,28}$ Nevertheless, the stress peaks in zirconia were not twice higher than for LD. The hardness property consists in the ability of the material to limit crack propagation. In zirconia, this process occurs through the volumetric increase of 3-4\% of the zirconia grains close to the crack due to the change of the tetragonal phase to the monoclinic phase.

Studies support that zirconia presents a higher value of fracture resistance and superior mechanical 

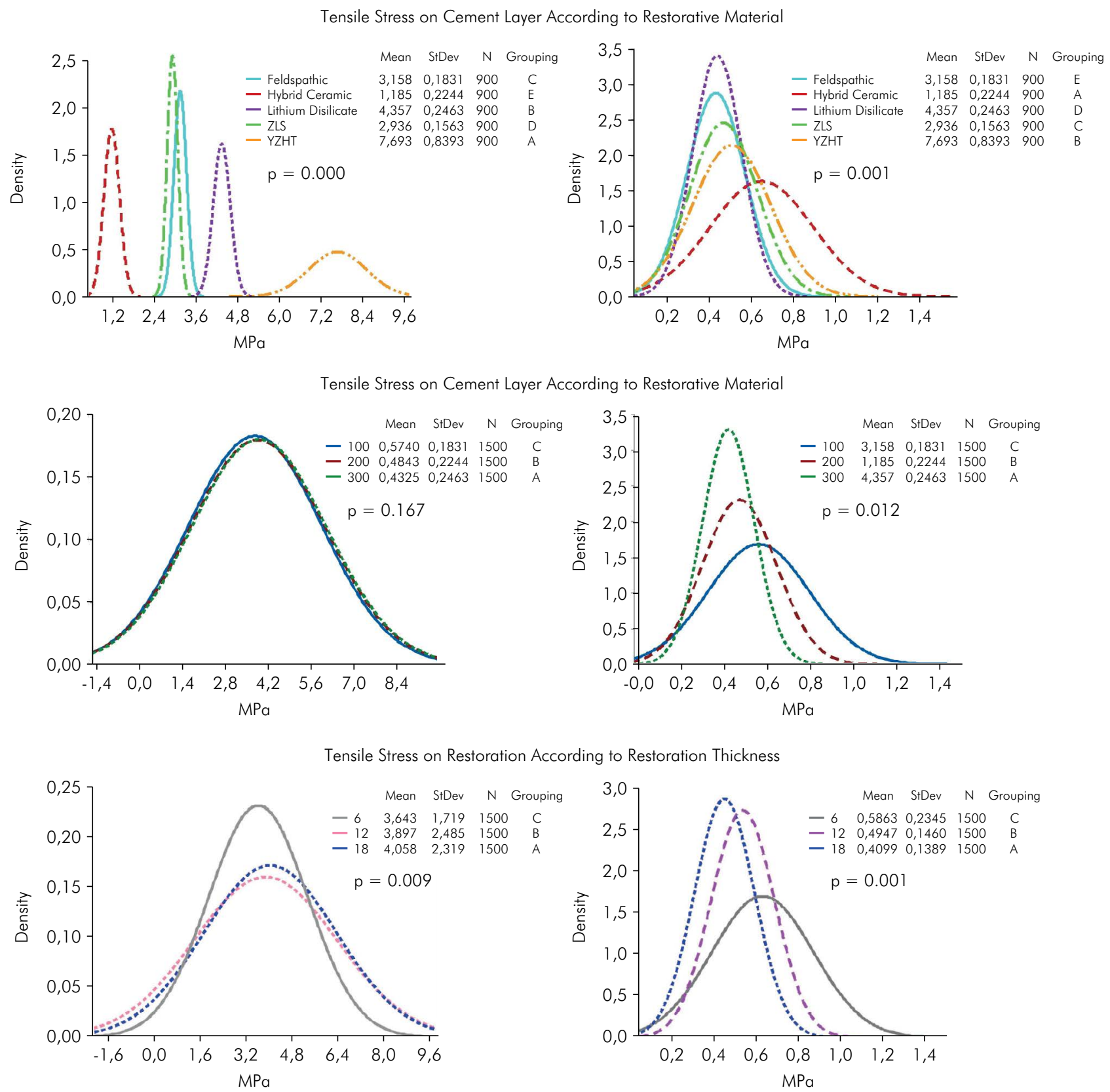

Figure 4. Histograms of tensile stress peaks at the adhesive interface. On the left, results obtained on the internal face of the restoration. On the right, results obtained in the cement layer. Factors from top to bottom are material, cement thickness, and restoration thickness. The graphs show descriptive statistics (means and standard deviations), and one-way ANOVA and Tukey's tests results ( $\alpha=5 \%)$.

properties than the ceramics evaluated herein..$^{19,20}$ The higher the percentage of crystals in the ceramic structure, the greater the difficulty to propagate the defect (slow crack growth). A crack originates when the structure is subjected to a stress associated with external factors, such as humidity. After crack formation, the structure fails when the employed stress exceeds the fracture resistance of the material..$^{29}$ The characteristic strength of a material under fatigue tends to be approximately half the flexural strength of the material. ${ }^{19}$

The results suggest that lithium disilicate is more reliable than feldspathic ceramics, because the difference between the tensile stress of these materials was significant $(<10 \%)$, yet close enough to predict that the 


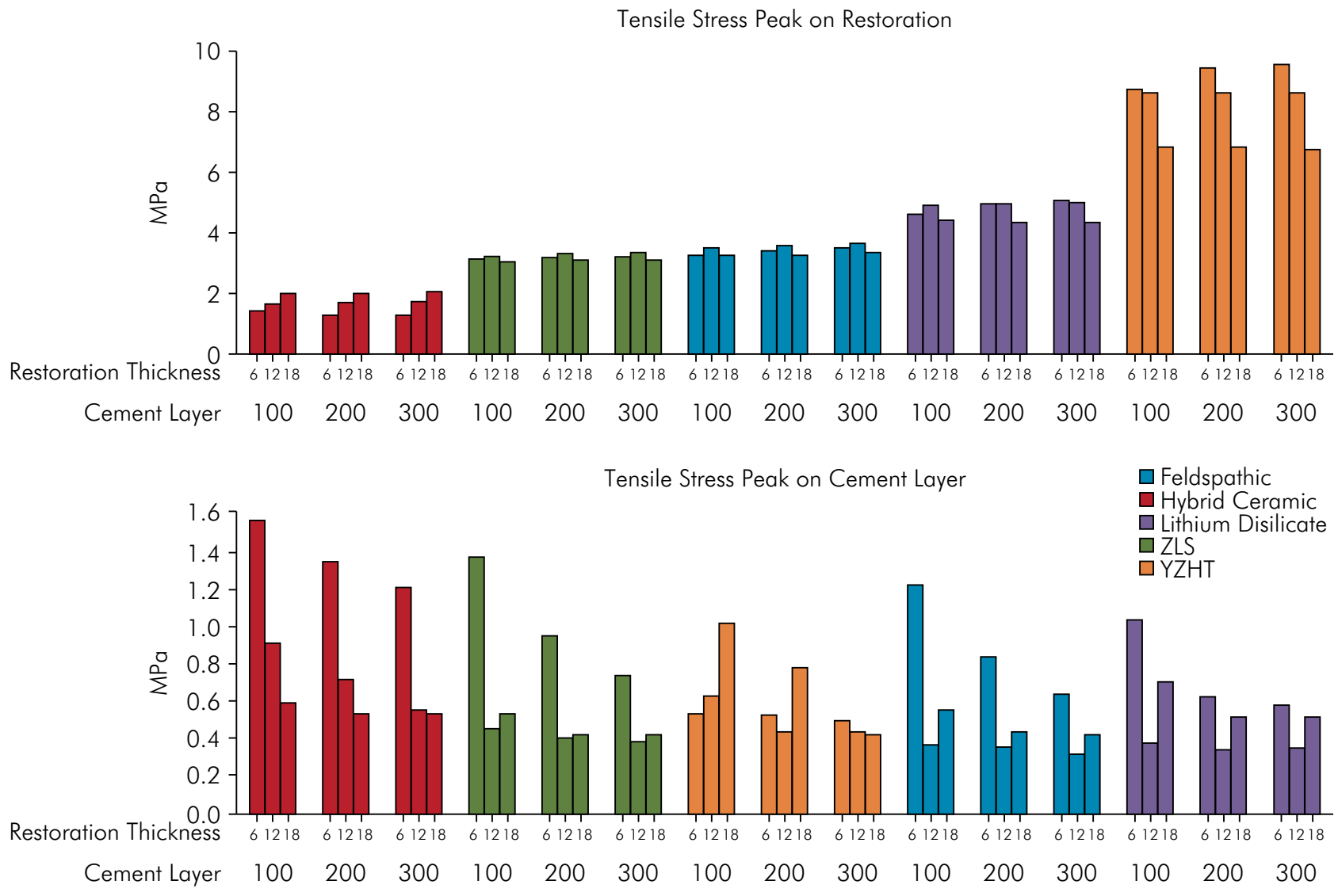

Figure 5. Bar graph of stress peaks generated in cement and restoration for all 45 groups.

critical stress of feldspathic will occur earlier, as force is applied. This suggests that, under the same conditions, a feldspathic ceramic crown would fail earlier than a crown in LD, as the feldspathic ceramic has a lower tensile strength value ${ }^{30}$ than $\mathrm{LD}$. Lithium disilicate has lower glass content ( $30-40 \%$ by volume) than feldspathic ceramic (more than $65 \%$ by volume) presenting a high degree of crosslinking, which prevents crack growth. Since we used a linear method and the complex geometry of the occlusal veneer was the same for both groups, it is possible to affirm that the slope of the graph line is similar for all materials. Thus, as feldspar has roughly three-fold less resistance than lithium disilicate ceramics, ${ }^{31}$ a lower stress peak may be more damaging to the vitreous material without reinforcement.

ZLS is not as rigid as lithium disilicate and the crystal reinforcement makes this material tougher than feldspathic ceramics ${ }^{21}$ due to its high glass content. ${ }^{32}$ However, the presence of zirconia in its structure is not shown to be beneficial for its resistance or survival. ${ }^{21}$
Also, lithium disilicate was shown to have superior mechanical results. ${ }^{21}$ Therefore, further studies with ZLS in occlusal veneer manufacturing are suggested.

The material with the lowest elastic modulus was the hybrid ceramic or ceramic infiltrated with polymer matrix. Under fatigue, a better performance is observed in polymer-based materials, ${ }^{5}$ and a lower risk of fracture is obtained in stress distribution studies ${ }^{4}$. A failure pattern not as serious as a catastrophic failure was also observed. ${ }^{5}$ In spite of this, the highest values of stress were found in the resin cement for the hybrid ceramics. This material cannot concentrate stress in its own structure, thus the adjacent geometry receives more energy and participates in the dissipation of occlusal forces with greater intensity. Hybrid ceramics may be a promising option for manufacturing a restoration (even with higher tensile strength generated in the resin cement), since the calculated stress peak was about 10 times smaller than in zirconia. In addition, due to the 
presence of a resinous matrix in its composition, the material has a different failure mode from the other simulated materials ${ }^{21}$ and a more reliable behavior. ${ }^{19}$

Crack propagation is associated with mechanical fatigue, such as hydraulic pumping, and moisture. ${ }^{33}$ However, in hybrid ceramics, the cracks propagate predominantly through the ceramic network and along the polymer/ceramic interface with polymer deformation bridges across the crack, which enhances the resistance to crack propagation. ${ }^{34,35}$. This characteristic does not make hybrid ceramics resistant to monotonic tests, ${ }^{36}$ but make them more reliable against fatigue. ${ }^{19,35}$ This result is similar to previous studies that found better mechanical properties in tabletop restorations made of materials with lower elastic modulus., ${ }^{4,5}$ The difference of the present study is that the simulated material was not a composite resin but a hybrid ceramic, thereby adding benefits of feldspar ceramics and composite resin. ${ }^{21}$

This study analyzed the influence of the restorative material thickness on the stress generated in the cement line, since an adhesive failure in the ceramic fragment can be inconvenient for patients and dentists. ${ }^{14}$ Although the increase in veneer thickness is beneficial because it increases strength ${ }^{6}$ absorbing more tensile stress, this paper is not suggesting that an eroded tooth should be prepared for a thicker veneer and thus undergo more tissue wear. Clinical success has been reported for restorations with the minimum thicknesses of $0.6 \mathrm{~mm}$. A simulation of thicker restorations demonstrated that if a patient presents high level of tooth wear, this therapeutic modality can still be used for rehabilitation by using the correct restorative material. ${ }^{6}$ The results show that the thicker the restoration, the lower the accumulated stress in the cement, thus suggesting that these restorations have a lower chance of debonding than thinner restorations. This finding is supported by studies that found similar behavior between restorations and cements both in thin buccal veneers that generate great accumulated stress in the cement line ${ }^{37}$ and by thick total crowns that protect the resin cement. ${ }^{38}$

The influence of occlusal veneer thickness on the cement layer performance has never been evaluated. Other studies used finite element analysis to assess this therapeutic modality, but did not simulate the cement line. ${ }^{4,11}$ It is important that all components of the restoration are simulated in a study, since the absence of the resin cement makes the system more rigid, and thus overestimates the calculated stress values. ${ }^{12}$ An ideal thickness is reported to be up to $120 \mu \mathrm{m} .{ }^{39}$ Higher compression during the restoration cementation facilitates the flow of the resin cement and decreases its thickness between the ceramic and the tooth..$^{14}$ As the simulated restoration is made of friable materials such as vitreous ceramics, covers one side of the tooth, and can be as thin as $0.6 \mathrm{~mm}$, the dentist could feel unsure about applying pressure to this ultrafine veneer during the cementation procedure. Articles describing the procedure for occlusal veneer restauration are no clear about the cementation step. ${ }^{2,5}$ With a thinner cement line, important factors to avoid are the premature teeth contact and changes in the final position of the restoration, which could cause early fatigue of the ceramic material. ${ }^{11}$ In addition, thicker cement layers can present more defects, inferior micromechanical adjustment, and higher water sorption and solubility of the adhesive/cement than thinner layers ${ }^{40}$ impairing the bond strength to the substrate.

The finite element analysis was essential to study 45 groups simultaneously, which would be too costly if using an in vitro experiment. Although it is a numerical analysis tool of biomechanical behavior and widely used in dental theoretical studies, ${ }^{4,11,12}$ this methodology has limitations and its results must be considered together with the literature to reach the best clinical decision. Limitations such as the use of isotropic materials, and absence of $\mathrm{pH}$, temperature, and biofilm simulation should be considered. The influence of other factors such as glazing or not the ceramics, different materials in the antagonist tooth, and the reactive dentin should be studied in future investigations.

\section{Conclusion}

Despite the limitations of this study, it was concluded that all simulated restorative materials can be used for occlusal veneers. However, hybrid ceramics stand out because they produce a lower stress concentration in the restoration structure. The thickness of the cement layer did not affect the mechanical performance of the restorations. Also, thicker occlusal veneers present superior mechanical 
performance than thinner restorations, but all three simulated conditions can withstand masticatory loads.

\section{Conflict of interest}

The authors declare no conflict of interest.

\section{References}

1. Abrahamsen TC. The worn dentition: pathognomonic patterns of abrasion and erosion. Int Dent J. 2005;55(4 Suppl 1):26876. https://doi.org/10.1111/j.1875-595X.2005.tb00064.x

2. Schlichting LH, Resende TH, Reis KR, Magne P. Simplified treatment of severe dental erosion with ultrathin CAD-

CAM composite occlusal veneers and anterior bilaminar veneers. J Prosthet Dent. 2016 Oct;116(4):474-82. https://doi.org/10.1016/i.prosdent.2016.02.013

3. Yazigi $C$, Kern M, Chaar MS. Influence of various bonding techniques on the fracture strength of thin CAD/CAM-fabricated occlusal glass-ceramic veneers. J Mech Behav Biomed Mater. 2017 Nov;75:504-11. https://doi.org/10.1016/i.jmbbm.2017.08.016

4. Magne P, Stanley K, Schlichting LH. Modeling of ultrathin occlusal veneers. Dent Mater. 2012 Jul;28(7):777-82. https://doi.org/10.1016/i.dental.2012.04.002

5. Magne P, Schlichting LH, Maia HP, Baratieri LN. In vitro fatigue resistance of $\mathrm{CAD} / \mathrm{CAM}$ composite resin and ceramic posterior occlusal veneers. J Prosthet Dent. 2010 Sep;104(3):149-57. https://doi.org/10.1016/S0022-3913(10)60111-4

6. Johnson AC, Versluis A, Tantbirojn D, Ahuja S. Fracture strength of CAD/CAM composite and composite-ceramic occlusal veneers. J Prosthodont Res. 2014 Apr;58(2):107-14. https://doi.org/10.1016/i.jpor.2014.01.001

7. Carvalho AO, Bruzi G, Giannini M, Magne P. Fatigue resistance of CAD/CAM complete crowns with a simplified cementation process. J Prosthet Dent. 2014 Apr;111(4):310-7. https://doi.org/10.1016/i.prosdent.2013.09.020

8. Lima JM, Souza AC, Anami LC, Bottino MA, Melo RM, Souza RO. Effects of thickness, processing technique, and cooling rate protocol on the flexural strength of a bilayer ceramic system. Dent Mater. 2013 Oct;29(10):1063-72. https://doi.org/10.1016/i.dental.2013.07.019

9. Ge C, Green CC, Sederstrom D, McLaren EA, White SN. Effect of porcelain and enamel thickness on porcelain veneer failure loads in vitro. J Prosthet Dent. 2014 May;111(5):380-7. https://doi.org/10.1016/i.prosdent.2013.09.025

10. Abu-lzze FO, Ramos GF, Borges ALS, Anami LC, Bottino MA. Fatigue behavior of ultrafine tabletop ceramic restorations. Dent Mater. 2018 Sep;34(9):1401-9. https://doi.org/10.1016/i.dental.2018.06.017

11. Magne P, Cheung R. Numeric simulation of occlusal interferences in molars restored with ultrathin occlusal veneers. J Prosthet Dent. 2017 Jan;117(1):132-7. https://doi.org/10.1016/i.prosdent.2016.07.008

12. Tribst JP, Dal Piva AM, Borges AL. Biomechanical behavior of indirect composite materials: a 3D-FEA study. Braz Dent Sci. 2017;20(3):52-7. https://doi.org/10.14295/bds.2017.v20i3.1444
13. Ausiello P, Ciaramella S, Martorelli M, Lanzotti A, Gloria A, Watts DC. CAD-FE modeling and analysis of class II restorations incorporating resin-composite, glass ionomer and glass ceramic materials. Dent Mater. 2017 Dec;33(12):1456-65. https://doi.org/10.1016/i.dental.2017.10.010

14. Prakki A, Cilli R, Costa AU, Gonçalves SE, Mondelli RF, Pereira JC. Effect of resin luting film thickness on fracture resistance of a ceramic cemented to dentin. J Prosthodont. 2007 May-Jun;16(3):172-8. https://doi.org/10.1111/j.1532-849X.2006.00168.x

15. Roscoe MG, Noritomi PY, Novais VR, Soares CJ. Influence of alveolar bone loss, post type, and ferrule presence on the biomechanical behavior of endodontically treated maxillary canines: strain measurement and stress distribution. J Prosthet Dent. 2013 Aug;110(2):116-26. https://doi.org/10.1016/S0022-3913(13)60350-9

16. Joshi S, Mukherjee A, Kheur M, Mehta A. Mechanical performance of endodontically treated teeth. Finite Elem Anal Des. 2001;37(8):587-601. https://doi.org/10.1016/S0168-874X(00)00059-7

17. Souza AC, Xavier TA, Platt JA, Borges AL. Effect of Base and Inlay Restorative Material on the Stress Distribution and Fracture Resistance of Weakened Premolars. Oper Dent. 2015 Jul-Aug;40(4):E158-66. https://doi.org/10.2341/14-229-L

18. Faria R, Bottino MA. High-translucent monolithic zirconia for implant-supported rehabilitations. Prótese News. 2016;3:36-50.

19. Homaei E, Farhangdoost K, Tsoi JK, Matinlinna JP, Pow $\mathrm{EH}$. Static and fatigue mechanical behavior of three dental CAD/CAM ceramics. J Mech Behav Biomed Mater. 2016 Jun;59:304-13. https://doi.org/10.1016/i.jmbbm.2016.01.023

20. Zimmermann M, Egli G, Zaruba M, Mehl A. Influence of material thickness on fractural strength of $C A D /$ CAM fabricated ceramic crowns. Dent Mater J. 2017 Nov;36(6):778-83. https://doi.org/10.4012/dmj.2016-296

21. Ramos NC, Campos TM, Paz IS, Machado JP, Bottino MA, Cesar PF, et al. Microstructure characterization and SCG of newly engineered dental ceramics. Dent Mater. 2016 Jul;32(7):870-8. https://doi.org/10.1016/i.dental.2016.03.018

22. Jongsma LA, de Jager N, Kleverlaan CJ, Pallav P, Feilzer AJ. Shear bond strength of three dual-cured resin cements to dentin analyzed by finite element analysis. Dent Mater. 2012 Oct;28(10):1080-8. https://doi.org/10.1016/j.dental.2012.07.002

23. Correia AMO, Tribst JPM, Matos FS, Platt JA, Caneppele TMF, Borges ALS. Polymerization shrinkage stresses in different restorative techniques for non-carious cervical lesions. J Dent. 2018 Sep;76:68-74. https://doi.org/10.1016/i.jdent.2018.06.010 
24. Dal Piva AMO, Tribst JPM, Borges ALS, Souza ROAE, Bottino MA. CAD-FEA modeling and analysis of different full crown monolithic restorations. Dent Mater. 2018 Sep;34(9):1342-50. https://doi.org/10.1016/i.dental.2018.06.024

25. Tribst JPM, Dal Piva AMO, Madruga CFL, Valera MC, Borges ALS, Bresciani E et al. Endocrown restorations: Influence of dental remnant and restorative material on stress distribution. Dent Mater. 2018 Oct;34(10):1466-73. https://doi.org/10.1016/j.dental.2018.06.012

26. Kok P, Pereira GK, Fraga S, Jager N, Venturini AB, Kleverlaan $C J$. The effect of internal roughness and bonding on the fracture resistance and structural reliability of lithium disilicate ceramic. Dent Mater. 2017 Dec;33(12):1416-25. https://doi.org/10.1016/i.dental.2017.09.018

27. Marinis A, Aquilino SA, Lund PS, Gratton DG, Stanford $C M$, Diaz-Arnold AM et al. Fracture toughness of yttria-stabilized zirconia sintered in conventional and microwave ovens. J Prosthet Dent. 2013 Mar;109(3):165-71. https://doi.org/10.1016/S0022-3913(13)60037-2

28. Zhang Y, Mai Z, Barani A, Bush M, Lawn B. Fracture-resistant monolithic dental crowns. Dent Mater. 2016 Mar;32(3):442-9. https://doi.org/10.1016/i.dental.2015.12.010

29. Scherrer SS, Lohbaver U, Della Bona A, Vichi A, Tholey MJ, Kelly JR et al. ADM guidance-ceramics: guidance to the use of fractography in failure analysis of brittle materials. Dent Mater. 2017 Jun;33(6):599-620. https://doi.org/10.1016/i.dental.2017.03.004

30. Trindade FZ, Valandro LF, Jager N, Bottino MA, Kleverlaan CJ. Elastic properties of lithium disilicate versus feldspathic inlays: effect on the bonding by 3D finite element analysis. J Prosthodont. 2018 Oct;27(8):741-7. https://doi.org/10.1111/jopr.12550

31. Zhang Y, Lee JJ, Srikanth R, Lawn BR. Edge chipping and flexural resistance of monolithic ceramics. Dent Mater. 2013 Dec;29(12):1201-8. https://doi.org/10.1016/i.dental.2013.09.004

32. Krüger S, Deubener J, Ritzberger C, Höland W. Nucleation kinetics of lithium metasilicate in $\mathrm{ZrO}$ 2-bearing lithium disilicate glasses for dental application. Int J Appl Glass Sci. 2013;4(1):9-19. https://doi.org/10.1111/ijag.12011

33. Zhang Y, Sailer I, Lawn BR. Fatigue of dental ceramics. J Dent. 2013 Dec;41(12):1135-47. https://doi.org/10.1016/i.jdent.2013.10.007

34. Coldea A, Swain MV, Thiel N. Hertzian contact response and damage tolerance of dental ceramics. J Mech Behav Biomed Mater. 2014 Jun;34:124-33. https://doi.org/10.1016/i.jmbbm.2014.02.002

35. El Zhawi H, Kaizer MR, Chughtai A, Moraes RR, Zhang Y. Polymer infiltrated ceramic network structures for resistance to fatigue fracture and wear. Dent Mater. 2016 Nov;32(11):135261. https://doi.org/10.1016/i.dental.2016.08.216

36. Al-Akhali M, Chaar MS, Elsayed A, Samran A, Kern M. Fracture resistance of ceramic and polymer-based occlusal veneer restorations. J Mech Behav Biomed Mater. 2017 Oct;74:245-50. https://doi.org/10.1016/i.jmbbm.2017.06.013

37. Jankar AS, Kale Y, Kangane S, Ambekar A, Sinha M, Chaware $S$. Comparative evaluation of fracture resistance of Ceramic Veneer with three different incisal design preparations - An In-vitro Study. J Int Oral Health. 2014 Feb;6(1):48-54.

38. Zhu J, Rong Q, Wang X, Gao X. Influence of remaining tooth structure and restorative material type on stress distribution in endodontically treated maxillary premolars: A finite element analysis. J Prosthet Dent. 2017 May; 117(5):646-55. https://doi.org/10.1016/i.prosdent.2016.08.023

39. Almeida e Silva JS, Erdelt K, Edelhoff D, Araújo É, Stimmelmayr M, Vieira LC et al. Marginal and internal fit of four-unit zirconia fixed dental prostheses based on digital and conventional impression techniques. Clin Oral Investig. 2014;18(2):515-23. https://doi.org/10.1007/s00784-013-0987-2

40. Silva NR, Souza GM, Coelho PG, Stappert CF, Clark EA, Rekow ED et al. Effect of water storage time and composite cement thickness on fatigue of a glass-ceramic trilayer system. J Biomed Mater Res B Appl Biomater. 2008 Jan;84(1):117-23. https://doi.org/10.1002/jbm.b.30851 